\title{
AVALIAÇÃO DE TECNOLOGIAS EM REATORES PARA PRODUÇÃO DE BIODIESEL A PARTIR DA ANÁLISE DOS PEDIDOS DE PATENTES
}

\author{
Joicy Manuela Vilanova Gois ${ }^{1 *}$; Dian Souza de Oliveira ${ }^{1}$; Rodolfo Romulo Araujo Chagas $^{1}$; Danilo \\ Francisco Corrêa Lopes ${ }^{2}$; Mikele Cândida Sousa Sant’Anna ${ }^{2}$; Gabriel Francisco da Silva ${ }^{1}$ \\ ${ }^{1}$ Universidade Federal de Sergipe - UFS - São Cristóvão/SE - Brasil \\ (joicy.manuela@hotmail.com) \\ ${ }^{2}$ Universidade Federal de Pernambuco - UFPE - Recife/PE - Brasil
}

\section{RESUMO}

O biodiesel é um combustível biodegradável, não tóxico, renovável e pode ser sintetizado por reatores do tipo contínuo ou do tipo batelada. Diante dessa situação, o presente estudo objetivou avaliar os avanços tecnológicos na área de reatores para produção de biodiesel. Para a realização da busca de patentes utilizou-se a base da World Intellectual Property Organization (WIPO), o Banco de dados do Instituto Nacional de Propriedade Industrial (INPI) e do European Patent Office (Espacenet). A atual prospecção foi realizada com o intuito de contribuir com o conhecimento sobre as pesquisas desenvolvidas, identificando os trabalhos na área de reatores para produção de biodiesel. Avaliando o cenário mundial e brasileiro podemos caracterizar a prospecção relativa ao uso de reatores para produção de biodiesel por estar em constante desenvolvimento. Os dados demonstram que a área é promissora no cenário brasileiro, tendo em vista o número relativamente baixo de pedidos de depósitos dessas tecnologias.

Palavras Chave: reatores, biodiesel, prospecção tecnológica.

\section{ABSTRACT}

The biodiesel is a biodegradable fuel, non-toxic, renewable and can be synthesized by continuoustype reactors or batch type. Given this situation, the present study aimed to evaluate the technological advances in the area of reactors for biodiesel production. To perform the search of patents used the base of the World Intellectual Property Organization (WIPO), the database of the National Institute of Industrial Property (INPI) and the European Patent Office (Spacenet). The current survey was conducted with the aim of contributing to the knowledge of the research developed by identifying the jobs in the area reactors for biodiesel production. Assessing the global scenario and Brazil we can characterize the exploration on the use of reactors for biodiesel production by being in constant development. The data demonstrate that the area is promising in the Brazilian scenario, given the relatively low number of applications for these technologies deposits.

Key words: reactor, biodiesel, technological forecasting

Área tecnológica: Biocombustíveis 


\section{INTRODUÇÃO}

Atualmente, tem-se procurado por formas de energia renováveis, que reduzam os impactos ao meio ambiente e que possam ser viáveis, quando comparada a utilização de outros combustíveis mais poluentes.

Dentro desse cenário, destaca-se o biodiesel, combustível alternativo, proveniente de fontes renováveis como óleos vegetais, gorduras animal e/ou residual, cuja utilização está associada à substituição de combustíveis fósseis em motores de ignição por compressão. (GOIS, 2012)

Trata-se de um combustível renovável, biodegradável e não tóxico. No Brasil, a produção de Biodiesel é crescente devido, principalmente, às excelentes condições naturais, propícias à implantação de diversas oleaginosas, mas também por causa dos incentivos governamentais.

Segundo Quintella et al. (2009), a prospecção tecnológica tem contribuído significativamente na geração de políticas de longo prazo, de estratégias e de planos, e na fundamentação nos processos de tomada de decisão referentes à pesquisa, ao desenvolvimento e à inovação (P\&D\&I). Desse modo, o presente trabalho tem como objetivo analisar as potencialidades, a evolução das competências tecnológicas e as características traduzidas através dos depósitos de patentes no que se refere à produção de biodiesel em reatores de um modo geral.

\section{DESCRIÇÃO DA TECNOLOGIA}

Segundo Morais (2011), a rota convencional para a produção de biodiesel é realizada em processo de batelada. Esta não exige muito gasto energético, nem cuidados especiais na operação e controle reacional, porém apresentam diversos problemas em relação à purificação dos produtos, aliados aos custos envolvidos no processo. Isso sugere a necessidade de se investigar novas rotas, a exemplo da rota continua. A diferença fundamental entre os processos em batelada e por rota contínua é a escala de produção. Para produzir de modo contínuo é necessário um grande investimento em automação e a garantia de uma quantidade considerável de matéria-prima para não interromper o processamento. Já o processo por batelada é bem mais flexível, podendo-se fazer uma nova mistura a cada batelada, mas a produção é mais reduzida.

Para os dois processos é possível construir uma infinidade de reatores, a exemplo de reatores do tipo RPA (reator perfeitamente agitado), PFR (reator de fluxo em pistão) ou reator em batelada. Esses reatores de diferentes modelos ou dimensões são capazes de automatizar e facilitar o processo de produção do biocombustível.

\section{METODOLOGIA}

Para o desenvolvimento da prospecção, foi tomado como base os pedidos de patentes depositados no European Patent Office (Espacenet - Worlwide), na World Intellectual Property Organization (WIPO) e no Banco de dados do Instituto Nacional de Propriedade Industrial (INPI). As palavraschave utilizadas na busca foram primeiramente "reator and biodiesel" no campo de busca "título", seguido de "reator and biodiesel" no campo de busca "título e resumo"; e suas respectivas traduções em inglês, quando utilizadas as bases internacionais.

Segundo Serafini e Silva (2011), para prospecção, um formato importante para agilizar buscas nas bases patentárias é a Classificação Internacional de Patentes (CIP), na qual as patentes são 
classificadas de acordo com a aplicação. São divididas em 8 seções, 21 subseções, 120 classes, 628 subclasses e 69000 grupos.

Os resultados foram expressos por frequência da classificação internacional de patentes (CIP), do país de origem de depósito e do ano de depósito. A pesquisa foi realizada no mês de setembro de 2012.

\section{RESULTADOS E DISCUSSÃO}

Utilizando-se a palavra-chave "reator and biodiesel", no campo "título e resumo" foram encontrados 23 resultados de documentos de patentes na base de dados INPI e, dentre eles, 74 classificações de CIP. Em pesquisas realizadas no banco de dados do INPI (Figura 1) foram encontradas 20 patentes desta classificação: processos químicos ou físicos, p. Ex., catálise, química coloidal; aparelhos pertinentes aos mesmos (B01J); 11 patentes desta classificação: combustíveis não incluídos em outro local; gás natural; gás natural de síntético obtido por processos não abrangidos pelas subclasses C10G ou C10K; gás liquefeito de petróleo; uso de aditivos em combustíveis ou ao fogo; acendedores de fogo (C10L); 10 patentes desta classificação: compostos acíclicos ou carbocíclicos (C07C); 7 patentes desta classificação: ácidos graxos derivados de gorduras, óleos ou ceras; velas; gorduras, óleos ou ácidos graxos resultantes da modificação química de gorduras, óleos, ou ácidos graxos obtidos dos mesmos (C11C); 7 patentes desta classificação: produção, p. ex., por compressão de matérias-primas ou por extração a partir de substancias de rejeitos, refinação ou preservação de óleos, substancias graxas, p. ex., lanolina, óleos graxos ou ceras; óleos essenciais; perfumes (C11B); 3 patentes desta classificação: separação (B01D); 2 patentes desta classificação: compostos macromoleculares obtidos por reações outras que não envolvendo ligações insaturadas carbono-carbono (C08G); 2 patentes desta classificação: fertilizantes orgânicos não abrangidos pelas subclasses C05B, C05C, p. ex., fertilizantes resultantes do tratamento de lixo ou refugos (C05F); 2 patentes desta classificação: mistura, p. ex., dissolução, emulsificação, dispersão (B01F) e 10 patentes de outras classificações.

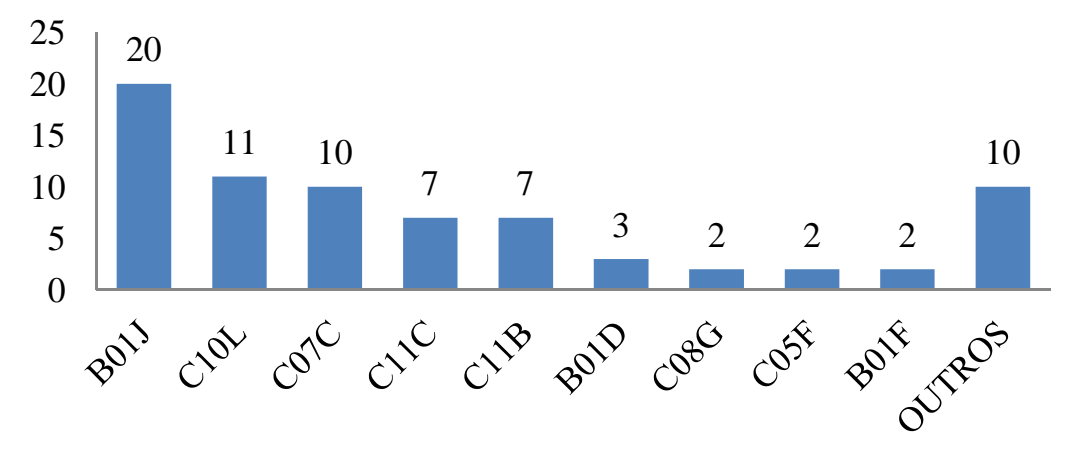

Figura 1: Número de documentos analisados no INPI pela CIP. Análise por subclasses com a palavra-chave reator and biodiesel no campo título e resumo. Fonte: Autoria própria, 2012.

Prosseguindo a pesquisa pelo banco de dados da Espacenet e utilizando a palavra-chave "reactor and biodiesel”. Quando se utiliza as palavras-chave já citadas no campo keywords in title or 
abstract 311 documentos de pedidos de depósito de patentes são disponibilizados (figura 2).

Dentre estes documentos acima citados, 107 patentes pertencem a esta classificação: combustíveis não incluídos em outro local; gás natural; gás natural de sintético obtido por processos não abrangidos pelas subclasses C10G ou C10K; gás liquefeito de petróleo; uso de aditivos em combustíveis ou ao fogo; acendedores de fogo (C10L); 99 patentes desta classificação: craqueamento de óleos hidrocarbonetos; produção de misturas hidrocarbonetos líquidos, p. ex., por hidrogenação destrutiva, oligomerização, polimerização; recuperação de óleos hidrocarbonetos de óleo de xisto, areia oleaginosa ou gases; refino de misturas principalmente consistindo de hidrocarboneto; reforma de nafta; ceras minerais (C10G); 74 patentes desta classificação: compostos acíclicos ou carbocíclicos (C07C); 68 patentes desta classificação: processos químicos ou físicos, p. Ex., catálise, química coloidal; aparelhos pertinentes aos mesmos (B01J); 63 patentes desta classificação: ácidos graxos derivados de gorduras, óleos ou ceras; velas; gorduras, óleos ou ácidos graxos resultantes da modificação química de gorduras, óleos, ou ácidos graxos obtidos dos mesmos (C11C); 19 patentes desta classificação: processos de fermentação ou processos que utilizem enzimas para sintetizar uma composição ou composto químico desejado ou para separar isômeros ópticos de uma mistura racêmica (C12P); 16 patentes desta classificação: produção, p. ex., por compressão de matérias-primas ou por extração a partir de substâncias de rejeitos, refinação ou preservação de óleos, substancias graxas, p. ex. , lanolina, óleos graxos ou ceras; óleos essenciais; perfumes (C11B); 13 patentes desta classificação: aparelhos para enzimologia ou microbiologia (C12M); 10 patentes desta classificação: separação (B01D) e 52 patentes de outras classificações.

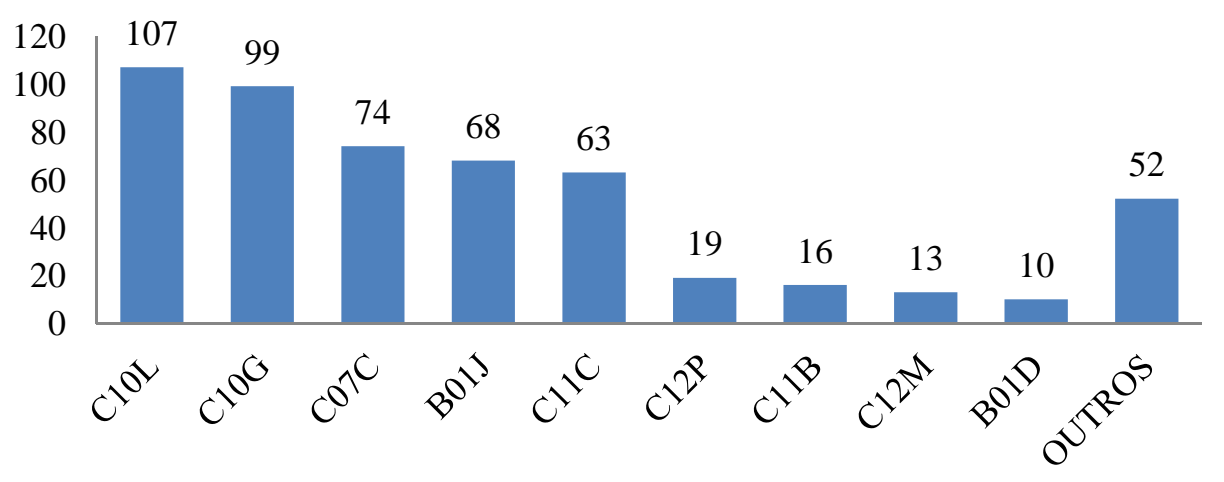

Figura 2: Número de documentos analisados na Espacenet pela CIP. Análise por subclasses com a palavra-chave reator and biodiesel no campo. Fonte: Autoria própria, 2012.

A base de dados WIPO também foi utilizada para dar continuidade e complemento à pesquisa. Essa base foi a que proporcionou o segundo maior número de pedidos, com 121 resultados (figura 3).

Dentre estes documentos acima citados, 41 patentes pertencem a esta classificação: combustíveis não incluídos em outro local; gás natural; gás natural de síntético obtido por processos não abrangidos pelas subclasses C10G ou C10K; gás liquefeito de petróleo; uso de aditivos em combustíveis ou ao fogo; acendedores de fogo (C10L); 17 patentes desta classificação: compostos acíclicos ou carbocíclicos (C07C); 17 patentes desta classificação: craqueamento de óleos hidrocarbonetos; produção de misturas hidrocarbonetos líquidos, p. ex., por hidrogenação destrutiva, oligomerização, polimerização; recuperação de óleos hidrocarbonetos de óleo de xisto, 
areia oleaginosa ou gases; refino de misturas principalmente consistindo de hidrocarboneto; reforma de nafta; ceras minerais (C10G); 17 patentes desta classificação: ácidos graxos derivados de gorduras, óleos ou ceras; velas; gorduras, óleos ou ácidos graxos resultantes da modificação química de gorduras, óleos, ou ácidos graxos obtidos dos mesmos (C11C); 10 patentes desta classificação: processos químicos ou físicos, p. Ex., catálise, química coloidal; aparelhos pertinentes aos mesmos (B01J); 4 patentes desta classificação: processos de fermentação ou processos que utilizem enzimas para sintetizar uma composição ou composto químico desejado ou para separar isômeros ópticos de uma mistura racêmica (C12P); 3 patentes desta classificação: tratamento de água, de águas residuais, de esgotos ou de lamas e lodos (C02F); 3 patentes desta classificação: aparelhos para enzimologia ou microbiologia (C12M); 1 patentes desta classificação: separação (B01D) e 1 patentes desta classificação: fertilizantes orgânicos não abrangidos pelas subclasses c05b, c05c, p. ex., fertilizantes resultantes do tratamento de lixo ou refugos (C05F).

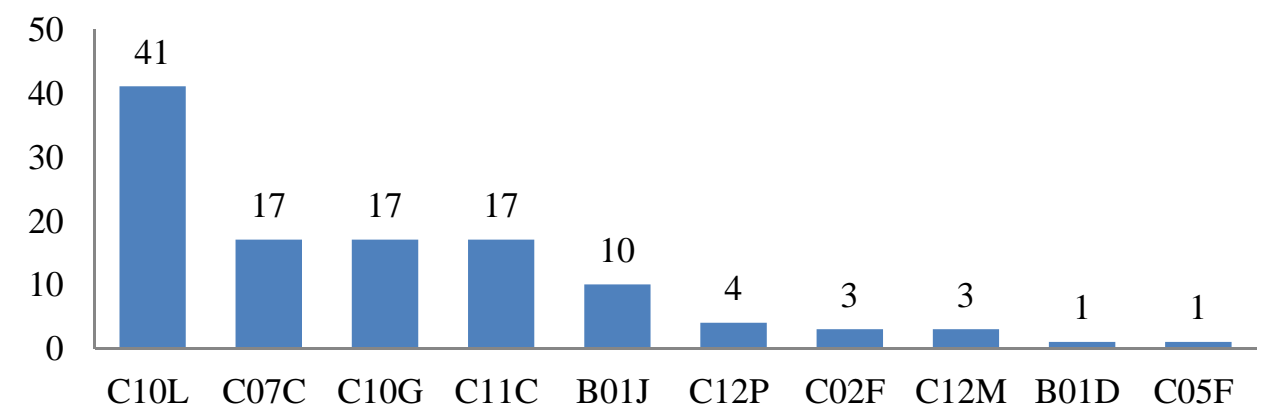

Figura 3: Número de documentos analisados no WIPO pela CIP. Análise por subclasses com as palavras-chave reactor and biodiesel. Fonte: Autoria própria, 2012.

Com objetivo de refinar a pesquisa, usou-se as mesmas palavras-chave ("reator and biodiesel), porém utilizando a subclasse "titulo” nas bases de busca. Para o INPI, foram encontrados apenas 3 documentos de patentes. Através do mesmo procedimento, encontrou-se 22 documentos de pedidos de depósito de patentes na base do Espacenet. Em relação às CIP, os códigos com maior número de pedidos de depósitos na base Espacenet para as palavras-chave reactor and biodiesel, no campo keywoards in tittle, foram B01J e C10L, com 12 e 10, respectivamente (Figura 4).

Outro dado interessante analisado nas bases de busca foi o número de depósitos por ano. Na base INPI, para a palavra-chave reator and biodiesel no campo título e resumo, o ano que apresentou o maior número de depósitos de patentes foi 2007, com 6 pedidos. (Figura 5). É possível verificar o número de documentos analisados no Espacenet por ano de depósito para a palavra-chave reator and biodiesel no campo keywords in title or abstract. Percebe-se que o ano de 2008 apresentou maior número de pedidos, com 60 documentos, seguido de 2007 com 52 documentos. Na coluna roxa (documentos encontrados na base WIPO), nota-se que o ano de 2009 foi o de maior número de pedidos de depósitos, totalizando 31 resultados.

A continuação da prospecção ocorreu analisando-se o número de pedidos de patentes por origem de depósito nos três bancos de dados utilizados. Como era previsto, na base INPI a grande maioria dos pedidos tem origem brasileira, porém resultados de outras nacionalidades também são encontrados, como visto na Figura 6. 


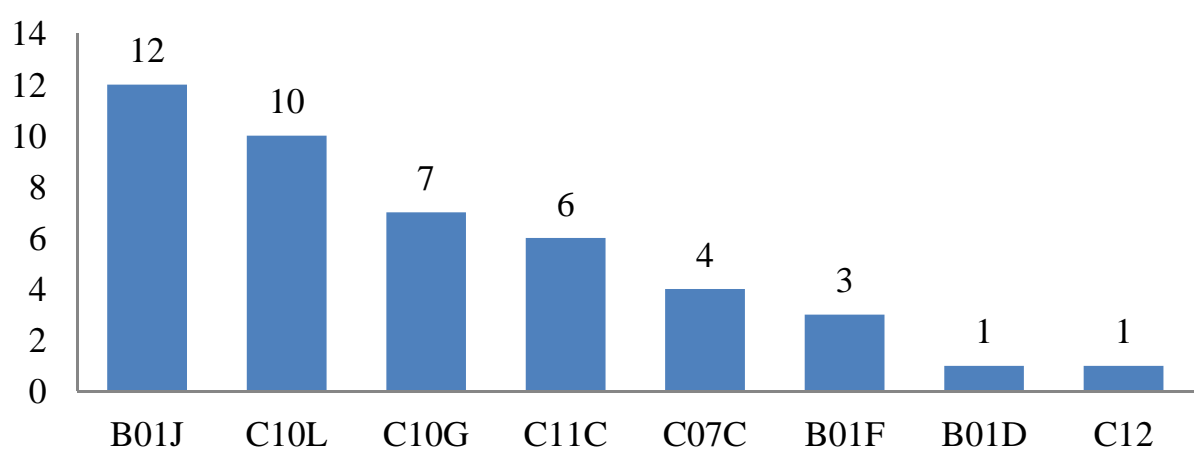

Figura 4: Número de documentos analisados na Espacenet pela CIP. Análise por subclasses com a palavra-chave reator and biodiesel no campo keywords in title. Fonte: Autoria própria, 2012.

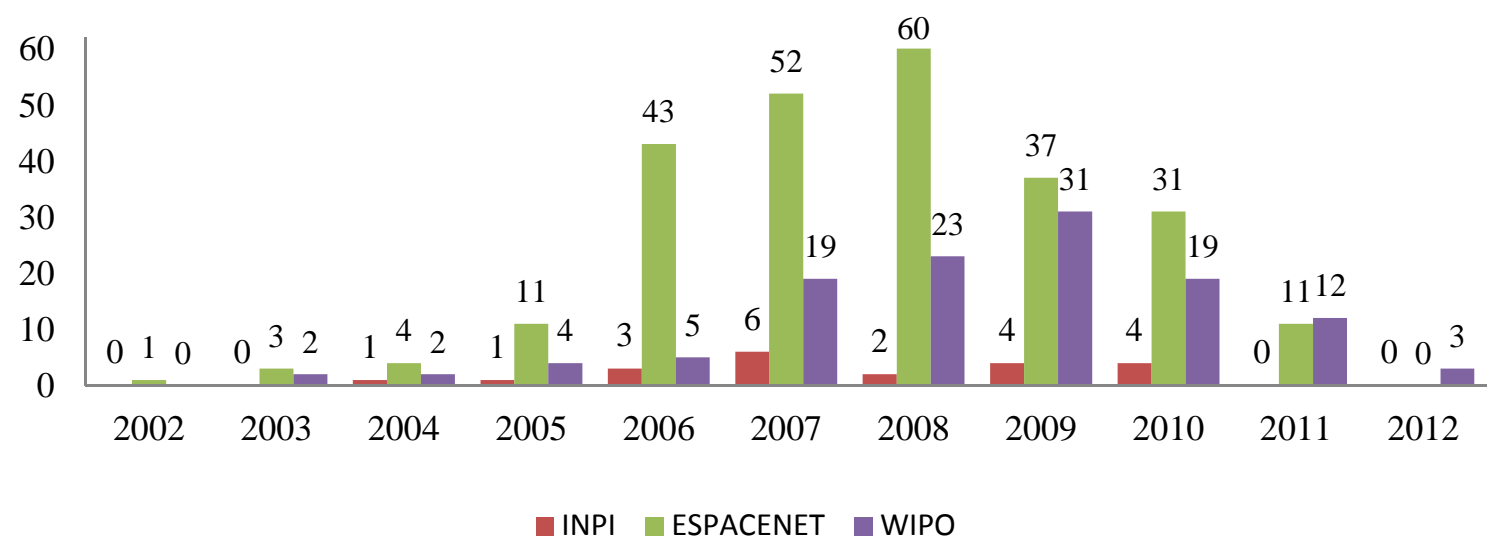

Figura 5: Número de documentos analisados no INPI, Espacenet e WIPO por ano de depósito para a palavra-chave reator and biodiesel. Fonte: Autoria própria, 2012.

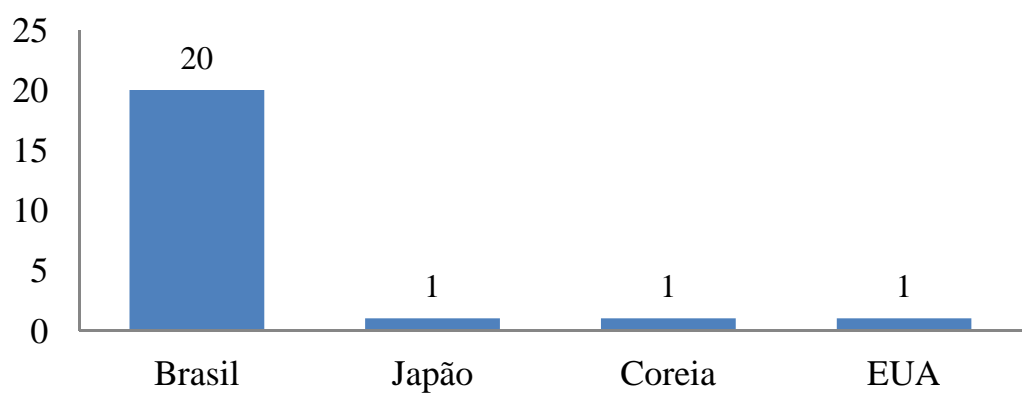

Figura 6: Número de documentos analisados no INPI por país depositante para a palavra-chave reator and biodiesel no campo Título e Resumo. Fonte: Autoria própria, 2012. 
Conforme a Figura 7, observamos que, na base do Espacenet, o país que apresentou mais pedidos de depósitos de patentes foi o China, com 176 resultados.

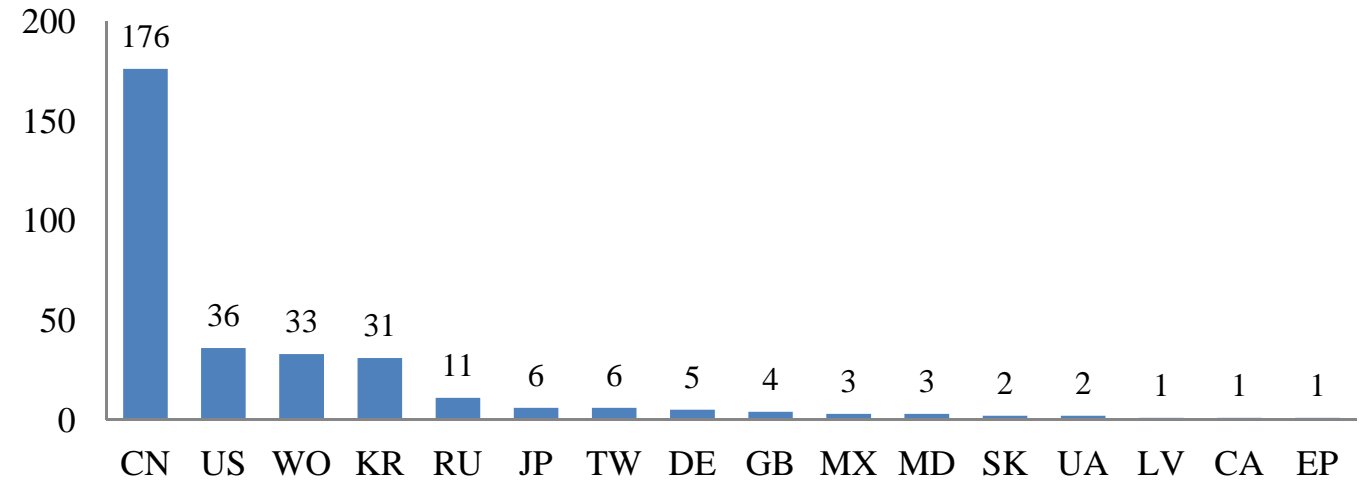

Figura 7: Número de documentos analisados no Espacenet por país depositante para a palavra-chave reator and biodiesel no campo keywords in title or abstract. Fonte: Autoria própria, 2012.

Em relação à origem de depósitos de patentes, PTC (Tratado de Cooperação de Patentes) foi quem apresentou o maior número de patentes depositadas na base do WIPO até a data da realização da prospecção, com o número de depósitos de 52. A Figura 8 ilustra o número de documentos analisados por origem de depósito.

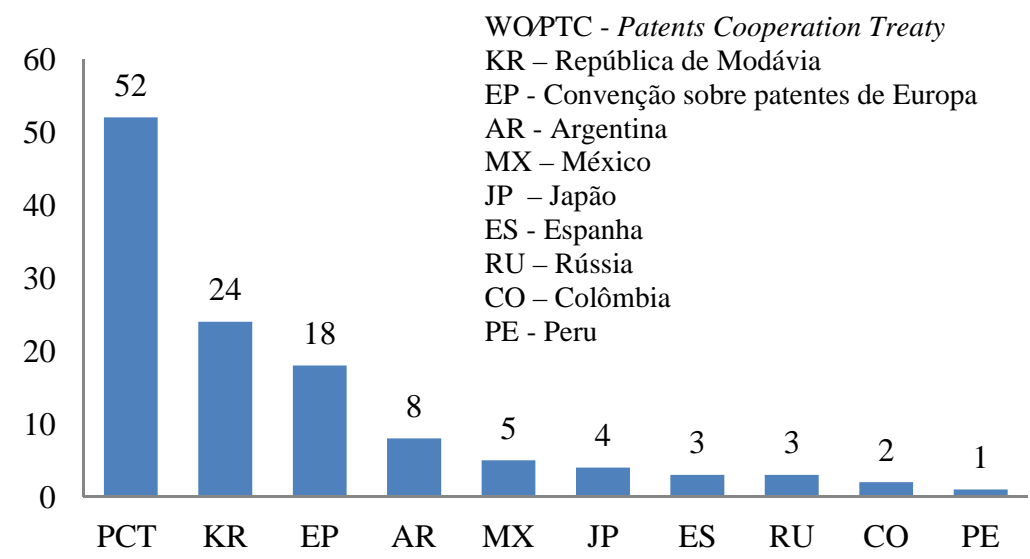

Figura 8: Número de documentos analisados no WIPO por origem de depósitos para as palavras-chave "reactor and biodiesel”. Fonte: Autoria própria, 2012.

Quando analisados os resultados de todas as bases de forma conjunta, percebe-se que o ano que apresenta o maior número de pedidos de patente é 2008, com 85 pedidos. Já em relação à origem do depósito, a China se destaca entre os demais, com 176 resultados (Figuras 9 e 10). 


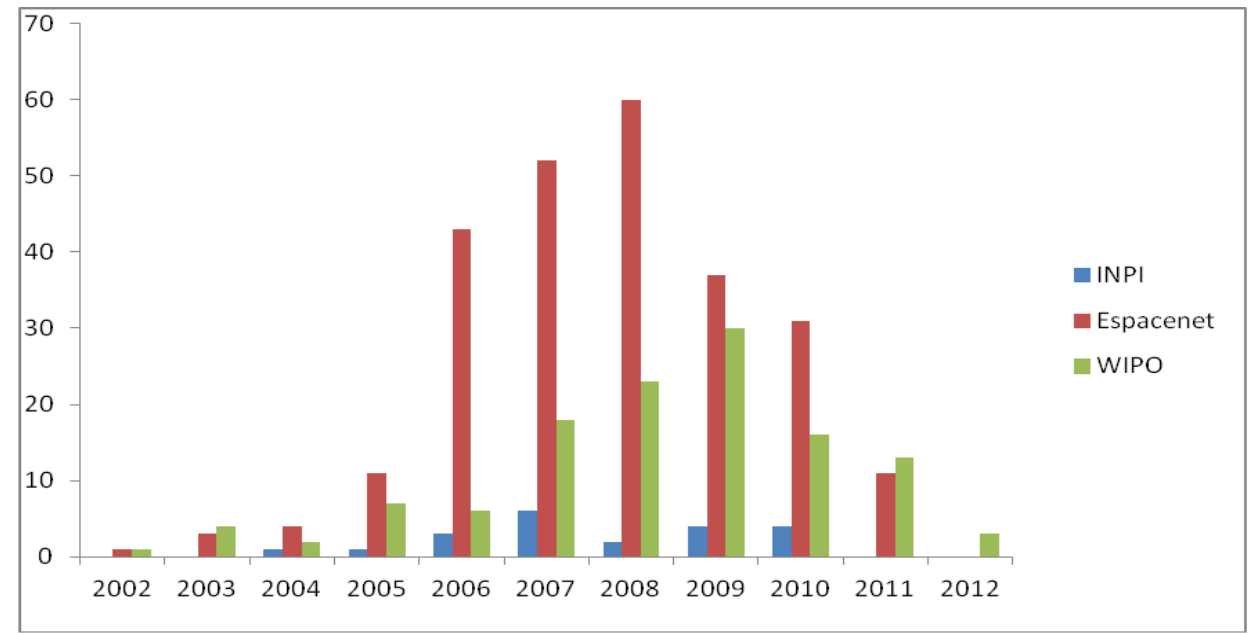

Figura 09: Número de documentos analisados nas bases (WIPO, Espacenet e INPI) por ano de depósito para as palavras-chave reactor and biodiesel no campo de busca título e resumo. Fonte: Autoria própria, 2012.

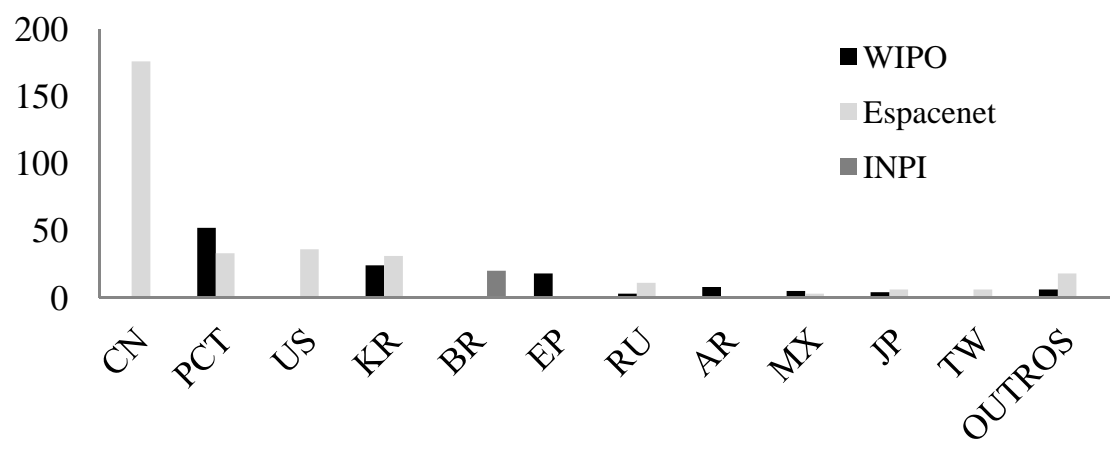

Figura 10: Número de documentos analisados nas bases (WIPO, Espacenet e INPI) por origem de depósito para as palavras-chave reactor and biodiesel no campo de busca título e resumo. Fonte: Autoria própria, 2012.

\section{CONCLUSÃO}

Avaliando o cenário mundial e brasileiro, no que concerne aos documentos de pedidos de patentes, podemos caracterizar a prospecção relativa ao uso de reatores para produção de biodiesel por apresentar um grande desenvolvimento, principalmente a partir do ano de 2006. Porém apresentou uma queda a partir do ano de 2011, principalmente nas classificações internacionais referentes a essa área. No cenário mundial, a China é o país que mais apresentou pedidos de patentes, demonstrando o alto grau de desenvolvimento nas pesquisas nessa área. Entretanto, os dados demonstram que, tratando-se de produção de biodiesel em reatores a área é promissora, tendo em vista o número relativamente baixo de pedidos de depósitos com essa tecnologia, principalmente no cenário brasileiro. Toda a avaliação foi feita no período do mês de setembro do ano 2012. 


\section{REFERÊNCIAS}

ANDRADE, A. D. S. Prospeç̧ão Tecnológica da Moringa. ENAM, Campina Grande, Paraíba. Universidade Federal de Sergipe. 2012

GOIS, J. M. V. Produção de biodiesel por processo contínuo. Artigo de iniciação científica. Universidade Federal de Sergipe, DEQ/UFS, 2012.

MORAIS, F. R. Desenvolvimento de um processo contínuo para produção de biodiesel a baixas temperaturas. 2011. . Dissertação (Mestrado em Engenharia química) - Universidade Federal de Sergipe, UFS, 2011.

QUINTELA, C.M.; C.M., TEIXEIRA; L.S.G., KORN M.G.A.; NETO, P. R. C.; TORRES, E. A.; CASTRO, M.; JESUS, C. A. C. Cadeia do Biodiesel da bancada à indústria: uma visão geral com prospecção de tarefas e oportunidades para P\&D\&I. Quím. Nova, v.32, n. 3, p. 793-808, 2009.

SERAFINI, M. R.; PAIXÃO, A. E.; JUNIOR, A. M. O.; SILVA, G. F. Avaliação de tecnologias em dessalinização de água a partir da análise dos pedidos de patentes. Revista GEINTEC, v.2, n. 1, p. 42-51, 2012.

SERAFINI, M. R.; SILVA, G. F. Prospecção Tecnológica no Brasil: Características da Propriedade Intelectual no Nordeste. . Revista GEINTEC, v.1, n. 1, p. 1-11, 2011. 